\title{
EFEITO ANTIMICROBIANO DA PRÓPOLIS CONTRA AGENTES INFECCIOSOS DE INTERESSE VETERINÁRIO
}

\author{
SOUZA, Francine Bretanha Ribeiro de ${ }^{1}$; \\ FISCHER, Geferson' \\ VARGAS, Gilberto D’Ávila².
}

\footnotetext{
${ }^{1}$ Mestranda do Programa de Pós-Graduação em Veterinária da UFPEL. ${ }^{2}$ Médico Veterinário, Professor Doutor da Faculdade de Veterinária da UFPEL.
}

\section{RESUMO}

\begin{abstract}
A
própolis é uma substância resinosa natural, produzida por abelhas melíferas a partir de exsudatos coletados em diferentes partes das plantas, que vem sendo utilizada

desde a antiguidade na medicina popular, tanto humana quanto veterinária, devido as suas propriedades terapêuticas. Embora determinados mecanismos de ação não estejam totalmente esclarecidos, este produto das abelhas tem sido relacionado à ação antisséptica, cicatrizante e antipirética. A atividade antimicrobiana é relatada em diversos estudos que utilizam como modelo experimental, diferentes gêneros de vírus, bactérias, fungos e parasitas. No entanto, achados controversos em relação à atividade da própolis como agente antimicrobiano são descritos, possivelmente devido à grande variabilidade química existente entre diferentes amostras de própolis, bem como das diferentes metodologias adotadas nos estudos científicos. Este artigo teve como objetivo revisar e discutir alguns aspectos relacionados à ação antimicrobiana da própolis sobre microrganismos de interesse veterinário.
\end{abstract}

Palavras-chave: Própolis. Antimicrobiano. Veterinária. 


\section{INTRODUÇÃO}

A história do desenvolvimento das civilizações é rica em exemplos da utilização de recursos naturais na medicina, no controle de pragas e em mecanismos de defesa (VIEGAS JR.; BOLZANI, 2006). O uso de plantas com fins medicinais, para tratamento, cura e prevenção de doenças é uma das formas mais antigas de prática medicinal da humanidade. Nos anos 90, foi divulgado pela OMS (Organização Mundial de Saúde), que grande parte da população dos países em desenvolvimento dependia das plantas como única forma de acesso aos cuidados básicos de saúde (VEIGA JÚNIOR; PINTO, 2005).

A própolis é um medicamento natural que vem sendo utilizado desde a antiguidade. Os Egípcios conheciam seus efeitos anti-putrefativos utilizando-a para embalsamar cadáveres. Os Gregos e Romanos reconheceram a própolis por suas propriedades medicinais, sendo utilizada como antisséptico e cicatrizante em feridas e desinfetantes bucais (CASTALDO; CAPASSO, 2002). Este efeito cicatrizante da própolis foi utilizado durante a Segunda Guerra Mundial em diversas clínicas na União Soviética (BARBOSA et al., 2009). A própolis também era utilizada por outras civilizações, como os Incas que a utilizavam como antipirético. Entre os séculos XVII e XX a própolis se tornou popular devido à sua ação antibacteriana (CASTALDO; CAPASSO, 2002).

A própolis é uma substância resinosa produzida por abelhas Apis mellifera. Esta substância é coletada de diversas partes da planta como brotos, botões florais e exsudatos resinosos (PARK et al., 2002). Uma vez coletada, essa substância é enriquecida com secreções enzimáticas e salivares (CASTALDO; CAPASSO, 2002). A própolis é utilizada para cobrir paredes da colmeia, preencher rachaduras e brechas, embalsamar insetos invasores mortos, reparar favos e manter o interior da colmeia asséptico, principalmente o local de postura da rainha (BANKOVA et al.,2000). A composição assim como a coloração da própolis depende da flora da região visitada pela abelha (PARK et al., 2002). Estudos mostram a grande variabilidade na sua composição (BANKOVA et al., 2000; LUSTOSA et al., 2008).

Mesmo sendo conhecida na medicina popular desde a antiguidade, a própolis tem atraído atenção de pesquisadores por sua utilidade na medicina e na cosmética, sendo amplamente estudada sua função antimicrobiana (SFORCIN et al., 2000). Inúmeros estudos relatando as 
propriedades biológicas da própolis já foram descritos (MARCUCCI, 1995; MARCUCCI, 1996; MENEZES, 2005).

Esta revisão tem por objetivo descrever os estudos realizados sobre a função antimicrobiana da própolis em microrganismos de interesse veterinário.

\section{ATIVIDADE ANTIVIRAL}

Em 1992, Amoros et al. avaliaram a atividade de um extrato etanólico de própolis, obtida da região de Rennes, na França, frente à alguns vírus in vitro, dentre eles o adenovírus canino tipo 2 (CAV-2) e o vírus da estomatite vesicular (VSV), que são de importância veterinária. Mesmo nas maiores concentrações do extrato etanólico de própolis testado, o CAV-2 não perdeu a infectividade. Já a infectividade do VSV foi reduzida a zero quando o vírus foi incubado por 120 minutos com o extrato etanólico de própolis na concentração de 500 $\mu \mathrm{g} / \mathrm{mL}$.

Cueto et al. (2011) relataram a atividade de um extrato etanólico de própolis contra o calicivirus felino (FCV), adenovírus canino tipo 2 (CAV-2) e o vírus da diarréia viral bovina (BVDV). Foram utilizados dois extratos etanólicos de própolis, um de própolis obtida da região central do estado Rio Grande do Sul (EP1), e outro adquirido de uma empresa de Minas Gerais (EP2). Três tipos de linhagens celulares foram utilizadas: MDBK (células de rim bovino), MDCK (células de rim canino) e CRFK (células de rim felino). Os extratos da própolis foram adicionados nas concentrações de 1500; 750; 375; 187,5; 93,75;46,8; 23,4; 11,7 $\mu \mathrm{g} \cdot \mathrm{mL}^{-1}$, em três períodos distintos: antes da inoculação do vírus, após a inoculação do vírus e antes e após a inoculação viral. Os melhores resultados foram obtidos quando o extrato da própolis foi adicionado antes da inoculação viral, sendo o efeito do EP1 superior ao EP2. Porém, ambos apresentaram melhor atividade contra o BVDV, do que contra o FCV e CAV-2. A análise cromatográfica dos extratos etanólicos de ambas as própolis indicou a presença de flavonóides como rutina, quercetina e ácido gálico, havendo uma maior quantidade de rutina no EP1. 
Fischer et al. (2005) testaram o efeito de uma solução de própolis verde contra o herpesvírus bovino tipo 1 e o vírus da diarréia viral bovina. Foram utilizadas duas suspensões de uma amostra de BoHV-1 e de uma amostra de BVDV, que foram incubadas com $1000 \mu \mathrm{g}$ de própolis. O tempo de incubação foi de zero e seis horas para a suspensão 1 do BoHV-1 e BVDV, e duas e oito horas para a suspensão 2 do BoHV-1 e BVDV. Houve inativação do BoHV-1 nas duas suspensões, quando incubadas à seis e oito horas. Já com o BVDV, ao contrário de Cueto et al. (2011), não se obtiveram resultados significativos.

Vilela et al. (2011) avaliaram o efeito virucida de um extrato etanólico de própolis verde contra o avipoxvirus na membrana corioalantóide de ovos embrionados. Os ovos foram inoculados com diferentes concentrações da própolis $(2400 \mu \mathrm{g} / \mathrm{dose}, 240 \mu \mathrm{g} /$ dose e 24 $\mu \mathrm{g} /$ dose) e submetidos à zero, quatro ou oito horas de incubação juntamente com o vírus. Após o período de incubação, avaliaram-se as lesões causadas pelo vírus (chamadas lesões pox) e o efeito da própolis. As lesões histopatológicas reduziram-se significativamente após oito horas de incubação e o número de lesões pox também se reduziu significativamente após as incubações, havendo inclusive ausência de lesões quando incubados com 2400 $\mu \mathrm{g} /$ dose de própolis. O extrato etanólico de própolis verde utilizado neste estudo foi previamente submetido a uma análise cromatográfica indicando a presença de grandes níveis de compostos fenólicos e de ácido cinâmico e seus derivados, e os flavonóides corresponderam a 22,37\% do extrato seco (FISCHER et al., 2007).

Kujumgiev et al. (1999) testaram extratos alcoólicos e voláteis de própolis provenientes de diferentes origens geográficas, sendo elas da Bulgária, Albânia, Mongólia, Egito, três regiões do Brasil (São Paulo, Ceará e Paraná) e duas regiões das llhas Canárias, contra o vírus da influenza aviária (H7N7). Os extratos etanólicos testados apresentaram efeito antiviral e porcentagens significativas de ácidos fenólicos e flavonóides em sua composição química, analisada por cromatografia gasosa e espectrometria de massa. Porém os extratos de própolis provenientes do Brasil não apresentaram ou apresentaram somente traços destes constituintes, havendo uma maior porcentagem de ácidos aromáticos. No entanto apresentaram atividade semelhante aos demais extratos. 


\section{ATIVIDADE ANTIBACTERIANA}

Em 1999, Bankova et al. avaliaram a atividade in vitro, contra Staphylococcus aureus e Escherichia coli, de óleos essenciais de três amostras de própolis, produzidas por três espécies de abelhas diferentes: Melipona compressites do estado do Piauí, Tetragona clavipes e Melipona quadrifasciata anthidioides do estado do Paraná. Pelo método de difusão verificou-se que os óleos essenciais das três amostras exerceram baixa atividade contra S. aureus e nenhuma atividade contra E. coli.

Sforcin et al. (2000) avaliaram o efeito de um extrato etanólico de própolis, coletada no estado de São Paulo, de acordo com a estação do ano em que ocorreu a coleta. Avaliou-se a ação antimicrobiana contra 15 cepas de S. aureus, cinco cepas de Pseudomonas aeruginosa, cinco de E. coli e cinco de Salmonella typhymurium. As amostras de própolis de cada estação ao ano foram testadas nas concentrações que variaram de 0,4 a $14,0 \%$. As cepas de $S$. aureus foram suscetíveis às concentrações mais baixas do extrato, obtendo-se $90 \%$ de inibição do crescimento em uma concentração de $0,6 \%$ do extrato etanólico de própolis. As bactérias Gram-negativas ( $P$. aeruginosa, $E$. coli e S. typhymutium) foram mais resistentes ao extrato, havendo inibição de $90 \%$ do crescimento em concentrações acima de $5 \%$. E não houve diferença estatística na concentração inibitória mínima dos extratos etanólicos das amostras de própolis coletadas em diferentes estações do ano.

Loguercio et al. (2006) conduziram um experimento avaliando a atividade in vitro de um extrato de própolis obtida da região de Santa Maria, no estado Rio Grande do Sul, em solução alcoólica a 50\%, contra agentes causadores da mastite bovina, sendo testado contra 63 linhagens bacterianas: 36 de Staphylococcus coagulase-positivas e 27 de Streptococcus spp. Dentre as amostras testadas, 90,5\% foram sensíveis ao extrato da própolis, sendo o efeito contra os isolados Staphylococcus coagulase-positivas superior aos de Streptococcus spp. $(94,4 \%$ contra $85,2 \%$, respectivamente).

Garcia et al. (2004), testaram o efeito in vitro e in vivo de um extrato alcoólico da própolis (EAP) sobre Pasteurella multocida, isolada de coelhos. A própolis foi obtida de três regiões diferentes do estado de São Paulo. No ensaio in vitro, o extrato alcoólico de própolis foi adicionado ao meio de cultura em três concentrações (5, 10 e 15\%). Após a inoculação da $P$. 
multocida nas placas contendo meio e EAP, essas foram incubadas e observadas com intervalos de $24 \mathrm{~h}$ para avaliação de crescimento microbiano. Como controle, utilizaram-se as mesmas concentrações de álcool etílico PA. No grupo controle, somente se observou inibição parcial do crescimento bacteriano com a adição de 15\% de álcool etílico PA no meio de cultura. Já as placas que receberam as diferentes concentrações do EAP apresentaram inibição total do crescimento bacteriano desde a primeira leitura (24 h), com exceção da primeira leitura nas placas com $5 \%$ de própolis proveniente de uma das regiões. 0 ensaio in vivo foi realizado a partir da adição de diferentes concentrações do extrato seco de própolis $(0,1 \%, 0,2 \%$ e $0,3 \%)$ na ração fornecida aos animais, sendo que o grupo controle recebeu ração pura. Observou-se o número de unidades formadoras de colônia (UFC) na região traqueobrônquica dos coelhos, antes e após o fornecimento das rações. Obteve-se redução significativa no número de UFC nas rações que continham 0,1 e 0,2\% de extrato seco de própolis.

Vargas et al. (2004) avaliaram a ação antibacteriana in vitro da própolis, obtida de apiários comerciais da região de Santa Maria, no estado do Rio Grande do Sul, em solução alcoólica a 50\% sobre 161 isolados bacterianos, 81 Gram-positivos (46 de Staphylococcus spp., 21 de Streptococcus spp., cinco de Rhodococcus equi e nove de Nocardia asteroides) e 80 Gramnegativos (29 de Pseudomonas aeruginosa, nove de Proteus mirabilis, 22 de Salmonella spp. e 20 de $E$. coli). Do total de amostras analisadas, 109 foram sensíveis ao extrato de própolis, sendo 75 Gram-positivas e 34 Gram-negativas. Dentre as amostras Gram-positivas, a N. asteroides apresentou $100 \%$ de sensibilidade, seguida por Staphylococcus spp. $(97,83 \%)$, Streptococcus spp. $(80,95 \%)$ e $R$. equi (80\%). As bactérias Gram-negativas testadas mostraram-se mais resistentes ao extrato de própolis do que as Gram-positivas. $P$. aeruginosa foi a Gram-negativa que apresentou maior sensibilidade ao extrato $(72,41 \%)$, seguida por P. mirabilis (33,30\%), E. coli (25\%) e Salmonella spp. (22,72\%).

Amostras de geoprópolis (composto de própolis e argila) de Melipona scutellaris obtidas na região de Entre Rios, no estado da Bahia, foram avaliadas quanto ao seu efeito antimicrobiano por Da Cunha et al. (2013). Foi testada a atividade antibacteriana do extrato etanólico da geoprópolis, e suas frações hexânica, clorofórmica e acetato de etila, em 
concentrações entre 3,125 a $1600 \mu \mathrm{g} / \mathrm{mL}$, contra Streptococcus mutans, S. aureus, S. aureus resistente à meticilina, Enterococcus faecalis, Actinomyces naes/undii e $P$. aeruginosa. As bactérias mais sensíveis, tanto ao extrato quanto às suas frações, foram as cepas de $S$. aureus, apresentando concentração bactericida mínima (CBM) e concentração inibitória mínima (CIM) menores que $50 \mu \mathrm{g} / \mathrm{mL}$. Já o crescimento da $P$. aeruginosa não foi inibido por nenhuma das concentrações testadas do extrato etanólico e suas frações. A fração que exerceu melhor atividade antibacteriana foi a fração hexânica do extrato etanólico, apresentando CIM entre 6,25 e $400 \mu \mathrm{g} / \mathrm{mL}$ e CBM entre 25 e $1600 \mu \mathrm{g} / \mathrm{mL}$, exceto para $P$. aeruginosa. Além disso, o extrato etanólico, na concentração de $25 \mu \mathrm{g} / \mathrm{mL}$, e sua fração hexânica, na concentração de $6,25 \mu \mathrm{g} / \mathrm{mL}$, inibiram $51 \%$ e $86 \%$, respectivamente, a formação de biofilme pelo S. mutans, bactéria que habita cavidade oral. A análise química do extrato etanólico e da sua fração hexânica apresentou picos similares, porém mais concentrado na fração hexânica. A análise cromatográfica indicou a presença de benzofenonas, porém não se observou a presença de flavonóides.

Righi et al. (2011) utilizaram um extrato metanólico de própolis vermelha coletada na região de Maceió, no estado de Alagoas, para avaliação da atividade antimicrobiana contra as bactérias Gram-positivas Bacillus subtilis, E. faecalis e Streptococcus pyogenes; Gramnegativas Klebsiella pneumoniae, P. aeruginosa, S. typhimurium e E. coli; e do fungo Candida albicans. $\mathrm{O}$ extrato inibiu o crescimento de todos os microrganismos testados, havendo uma maior sensibilidade das bactérias Gram-positivas do que as Gram-negativas ao extrato. Um extrato etanólico de própolis vermelha, obtida de um apiário de abelhas A. mellifera também do estado de Alagoas, e sua fração clorofórmica, foram submetidos à avaliação de sua atividade antibacteriana contra S. aureus por Cabral et al. (2009). Na análise cromatográfica da fração clorofórmica e do extrato etanólico foram identificados os compostos quercetina (flavonóide), formonetina e daidzeina (isoflavonas) e os ácidos fenólico e ferúlico, não havendo diferença estatística na quantidade de fenólicos totais entre ambos. A atividade contra a bactéria testada foi potencializada quando utilizada a fração clorofórmica do extrato etanólico da própolis vermelha, sendo a CBM e a CIM da fração clorofórmica $50 \%$ menor que a do extrato etanólico. 
Cardoso et al.(2010) realizaram um estudo onde se avaliou o efeito de um extrato etanólico de própolis, obtida da região de Santa Maria, estado do Rio Grande do Sul, contra os principais agentes isolados de otite canina, Staphylococcus coagulase-positivas (S. aureus e Staphylococcus intermedius) e Malassezia pachydermatis. As concentrações de própolis utilizadas para avaliar a concentração bactericida mínima (CBM) foram de $42,8 \mathrm{mg} \cdot \mathrm{mL}^{-1}$ à 0,69 mg.mL ${ }^{-1}$. A concentração bactericida mínima encontrada neste estudo foi de 21 $\mathrm{mg} \cdot \mathrm{mL}^{-1}$ para os agentes bacterianos estudados. Oliveira et al. (2010) testaram óleo essencial extraído de uma amostra de própolis obtida no estado do Rio de Janeiro no mês de julho. O óleo foi submetido à cromatografia gasosa e espectrometria de massa onde se observou que os componentes em maior quantidade foram $\beta$-caryophillene $(12,7 \%)$, acetophenone (12,3\%) e linalool (6,47\%). A atividade antibacteriana do óleo foi testada pelo método de difusão em disco contra S. aureus, Staphylococcus epidermides, $S$ pyogenes e $E$. coli. O óleo apresentou atividade antibacteriana contra todas as bactérias testadas não havendo diferença estatística entre elas.

Kujumgiev et al. (1999) também testaram o efeito antibacteriano dos extratos de própolis obtidas de diferentes localidades contra S. aureus e E. coli. As amostras somente apresentaram efeito contra a bactéria Gram positiva S. aureus.

Um estudo avaliando a atividade in vitro de extratos metanólicos, nas concentrações entre 64 e $0,25 \mu \mathrm{g} / \mathrm{mL}$, de vinte amostras de própolis de origem cubana, entre elas amostras de própolis vermelha, marrom e amarela, contra bactérias e fungos foi desenvolvido por Monzote et al. (2012). A avaliação antibacteriana foi realizada contra as bactérias S. aureus e E. coli. Todas as amostras apresentaram atividade contra o S. aureus nas concentrações mínimas, porém nenhum dos extratos, mesmo em altas concentrações, apresentou atividade contra a E. coli.

A ação antibacteriana da própolis é evidenciada principalmente sobre as bactérias Grampositivas. Apesar de haver efeito contra as bactérias Gram-negativas, as Gram-positivas mostraram-se mais suscetíveis à própolis, sendo este fato atribuído à ação dos compostos presentes na própolis sobre a parede celular das bactérias Gram-positivas. E apesar da parede celular das bactérias Gram-negativas não ser tão rígida quanto as Gram-positivas, é 
quimicamente mais complexa e possui maior teor lipídico que as Gram-positivas (VARGAS et al., 2004).

\section{ATIVIDADE ANTIFÚNGICA}

A própolis possui também atividade antifúngica, sendo esta demonstrada em diversos estudos. Entre eles, o realizado por Fernandes et al. (2007) que avaliaram a atividade de um extrato etanólico de própolis verde contra o Cryptococcus neoformans e observaram o efeito inibitório do crescimento fúngico com extrato etanólico da própolis na concentração 0,2 $\mathrm{mg} \cdot \mathrm{mL}^{-1}$.

Extrato alcoólico de própolis verde, proveniente da região de Belo Horizonte, e de própolis vermelha, proveniente da Paraíba, fornecidos pela empresa Pharma Néctar ${ }^{\circledR}$, foram testados contra três espécies de Trichophyton spp. (T. rubrum, $T$. tonsurans e $T$. mentagrophytes), nas concentrações 0,03 a $1024 \mu \mathrm{g} \cdot \mathrm{mL}^{-1}$ (SIQUEIRA et al., 2009). O extrato etanólico de própolis verde apresentou concentração mínima fungicida de $1024 \mu \mathrm{g} \cdot \mathrm{mL}^{-1}$ para as espécies $T$. rubrum e $T$. tonsurans, e $512 \mu \mathrm{g} \cdot \mathrm{mL}^{-1}$ para $T$. mentagrophytes. Já a concentração mínima fungicida do extrato de própolis vermelha foi $128-256,128-1024$ e $256-512 \mu \mathrm{g} \cdot \mathrm{mL}^{-1}$ para $T$. rubrum, $T$. tonsurans e $T$. mentagrophytes, respectivamente.

Monzote et al. (2012) também avaliaram a atividade antifúngica dos extratos metanólicos, também nas concentrações entre 64 e $0,25 \mu \mathrm{g} / \mathrm{mL}$, de vinte amostras de própolis cubanas contra T. rubrum e C. albicans. Houve atividade contra o T. rubrum em baixas concentrações, já contra a C. albicans nem mesmo as mais altas concentrações testadas exerceram atividade.

Kujumgiev et al. (1999) testaram o efeito de extratos etanólicos de própolis de diversas regiões contra $C$. albicans, sendo que todas as amostras de própolis apresentaram efeito inibitório contra o agente fúngico. Cardoso et al. (2010) também avaliaram o efeito antimicrobiano da própolis contra $M$. pachydermatis, outro agente causador de otite canina. A concentração fungicida mínima encontrada neste estudo foi de 5,3 mg. $\mathrm{mL}^{-1}$. 


\section{ATIVIDADE ANTIPARASITÁRIA}

Gressler et al. (2012) testaram um extrato etanólico de própolis, obtida da região central do estado do Rio Grande do Sul, contra o protozoário Trypanosoma evansi. Foram realizados testes in vitro e em animais infectados experimentalmente. Avaliou-se a susceptibilidade in vitro de tripomastigotas à própolis nas concentrações $0,0,5,1,5$ e $10 \mu \mathrm{g} \cdot \mathrm{mL}^{-1}$, havendo contagem dos tripanossomas restantes após 1, 3, 6, 9 e 24 horas. A concentração de 5 $\mu \mathrm{g} \cdot \mathrm{mL}^{-1}$ reduziu significativamente o número de parasitas após 1 hora, não havendo observação de parasitas vivos na concentração $10 \mu \mathrm{g} \cdot \mathrm{mL}^{-1}$ após uma hora. Para a avaliação in vivo foram utilizadas 36 ratas, que foram divididas em seis grupos, sendo cinco grupos submetidos à infecção por tripanossomas. Além dos controles, positivo (infectado e não tratado) e negativo (não infectado e não tratado), os demais grupos compreendiam animais tratados com doses que variaram de $100 \mathrm{mg} \cdot \mathrm{kg}^{-1}$ a $400 \mathrm{mg} \cdot \mathrm{kg}^{-1}$ do extrato de própolis. Não foram observados sinais de intoxicação pela própolis nos animais. No grupo que recebeu 400 mg.kg ${ }^{-1}$ observou-se um aumento no tempo de vida, quando comparado ao grupo controle positivo.

A atividade contra trofozoítos de Giardia duodenalis de um extrato hidroalcoólico de própolis, obtida de um apiário em São Paulo, foi avaliada por Freitas et al. (2006). Observouse redução de $50 \%$ ou mais no crescimento dos parasitas nas concentrações entre 125 $\mu \mathrm{g} / \mathrm{mL}$ e $500 \mu \mathrm{g} / \mathrm{mL}$, em todos os períodos de incubação $(24,48,72$ e 96 horas).

\section{CONCLUSÃO}

A própolis é um importante produto natural, conhecido popularmente por seus efeitos cicatrizante e antisséptico. A ação antimicrobiana, in vitro, assim como a composição de própolis obtidas de diferentes regiões vêm sendo estudadas contra diversos agentes de interesse humano e veterinário. A própolis demonstrou efeito contra diversos agentes de interesse veterinário in vitro, sendo este efeito dose dependente. Entretanto, poucos estudos in vivo foram desenvolvidos, restando uma grande lacuna a ser preenchida, não somente em relação a outras espécies como também em relação a outras vias de administração. 


\section{ANTIMICROBIAL EFFECT OF PROPOLIS ON INFECTIOUS AGENTS OF VETERINARY INTEREST}

\section{ABSTRACT}

D ropolis is a natural resinous substance produced by honeybees from exudates collected of different parts of the plant and it has been used as a therapeutic compound since antiquity in popular both human and veterinary medicine due to its therapeutics properties. Although the specific mechanism of action is not completely elucidated, this product has been associated with antiseptic, healing and antipyretic properties. The antimicrobial activity is described in various studies using different viruses, fungus, bacterias and parasites as experimental models. However, controversial findings related to the activity of propolis as an antimicrobial agent are described most likely due to the chemical variability existent among different samples of propolis as well as the adoption of different methods in the scientific studies. The objective of the present work is to review and discuss some relevant aspects related to the antimicrobial activity of propolis on infectious agents of veterinary interest.

Keywords: Propolis. Antimicrobial. Veterinary.

\section{EFECTO ANTIMICROBIANO DEL PROPÓLEOS EN AGENTES DE INTERÉS VETERINARIO}

\section{RESUMEN}

$\mathrm{E}$

propóleos es una sustancia resinosa natural producida por las abejas melíferas a partir de exudados colectados de diferentes partes de las plantas, que se ha utilizado desde la antigüedad en la medicina popular, tanto humana como veterinaria, debido a sus propiedades terapéuticas. Aunque ciertos mecanismos de acción no están completamente aclarados, este producto de las abejas ha sido relacionado con acciones antiséptica, cicatrizante y antipirética. La actividad antimicrobiana ha sido reportada en varios estudios usando como modelos experimentales diferentes tipos de virus, bacterias, hongos y parásitos. Sin embargo, se describen resultados controvertidos en relación con la actividad de los propóleos como agente antimicrobiano, posiblemente debido a la gran variabilidad química entre diferentes muestras de propóleos, así como por las diferentes metodologías utilizadas en estudios científicos. Este artículo tiene como objetivo revisar y discutir algunos aspectos relacionados con la acción antimicrobiana de propóleos sobre los microorganismos de interés veterinario.

Palabras clave: Propóleos. Antimicrobiano. Veterinaria. 


\section{REFERÊNCIAS}

AMOROS, M.; SAUVAGER, F.; GIRRE, L. et al. In vitro antiviral activity of propolis. Apidologie, v. 23, p. 231-240, 1992.

BANKOVA, V.; CHRISTOV, R.; POPOV, S. et al. Antibacterial activity of essential oils from Brazilian propolis. Fitoterapia, v. 70, n. 1999, p. 190-193, 1999.

BANKOVA, V. S.; CASTRO, S. L.; MARCUCCI, M. C. Propolis: recent advances in chemistry and plant origin. Apidologie, v. 31, n. 1, p. 3-15, jan./fev. 2000.

BARBOSA, M. H.; ZUFFI, F. B.; MARUXO, H. B. et al. Ação terapêutica da própolis em lesões cutâneas, Acta Paulista de Enfermagem, v. 22 n. 3, p. 318-322, 2009.

CABRAL, I. S. R.; OLDONI, T. L. C.; PRADO, A. et al. Composição fenólica, atividade antibacteriana e antioxidante da própolis vermelha brasileira. Química Nova, v. 32, n. 6, p. 1523-1527, 2009.

CARDOSO, R.L.; MABONI, F.; MACHADO, G. et al. Antimicrobial activity of propolis extract against Staphylococcus coagulase positive and Malassezia pachydermatis of canine otitis. Veterinary Microbiology, v. 142, n. 3-4, p. 432-434, 2010.

CASTALDO, S.; CAPASSO, F. Propolis, an old remedy used in modern medicine. Fitoterapia, v. 1, p. 1-6, 2002.

CUETO, A. P.; ALVES, S. H.; PILAU, M. et al. Atividade antiviral do extrato de própolis contra o calicivírus felino, adenovírus canino 2 e vírus da diarréia viral bovina. Ciência Rural, v. 41, n. 10, p. 1800-1806, 2011.

DA CUNHA, M. G.; FRANCHIN, M.; GALVÃO, L. C. C. et al. Antimicrobial and antiproliferative activities of stingless bee Melipona scutellaris geopropolis. BMC Complementary and Alternative Medicine, v. 13, n. 23, 2013.

FERNANDES, F. F.; DIAS, A. L. T.; RAMOS, C. L. et al. The in vitro antifungal activity evaluation of propolis $12 \mathrm{~g}$ ethanol extract on cryptococcus neoformans. Revista do Instituto de Medicina Tropical de São Paulo, v. 49, n. 2, p. 93-95, 2007.

FISCHER, G.; DUMMER, L. A.; VIDOR, T. et al. Avaliação da ação antiviral de uma solução de própolis sobre o Herpesvírus Bovino e o Vírus da Diarréia Viral dos Bovinos. In: EnPos Encontro de Pós-Graduação, 7, 2005, Pelotas. Anais, 2005.

FISCHER, G.; CONCEIÇÃO, F. R.; LEITE, F. P. L. et al. Immunomodulation produced by green própolis extract on humoral and cellular responses of mice immunized with SuHV-1. Vaccine, v. 25, p. 1250-1256, 2007. 
FREITAS, S. F.; SHINOHARA, L.; SFORCIN, J. M. et al. In vitro effects of propolis on Giardia duodenalis trophozoites. Phytomedicine, v. 13, p. 170-175, 2006.

GARCIA, R. C.; SÁ, M. E. P.; LANGONI, H. et al. Efeito do extrato alcoólico de própolis sobre a Pasteurella multocida in vitro e em coelhos. Acta Scientiarum Animal Sciences, v. 26, n. 1, p. 69-77, 2004.

GRESSLER, L. T.; SILVA, A. S.; MACHADO, G. et al. Susceptibility of Trypanosoma evansi to propolis extract in vitro and in experimentally infected rats. Research in Veterinary Science, v. 93, p. 1314-1317, 2012.

LOGUERCIO, A. P.; GROFF, A. C. M; PEDROZZO, A. F. et al. Atividade in vitro do extrato de própolis contra agentes bacterianos da mastite bovina. Pesquisa agropecuária brasileira, $\mathrm{v}$. 41, n. 2, p. 347-349, 2006.

LUSTOSA, S. R.; GALINDO, A. B.; NUNES, L. C. C. et al. Própolis: atualizações sobre a química e a farmacologia, Revista Brasileira de Farmacognosia, v. 18, n. 3, p. 447-454, 2008.

KUJUMGIEV, A.; TSVETKOVA, I.; SERKEDJIEVA, Y. et al. Antibacterial, antifungal and antiviral activity of propolis of different geographic origin. Journal Ethnopharmacol, v. 64, p. 235-240, 1999.

MARCUCCI, M. C. Propolis: a chemical composition, biological properties and therapeutic activity. Apidologie, v. 26, p. 83-99, 1995.

MARCUCCI, M. C. Propriedades biológicas e terapêuticas dos constituintes químicos da própolis. Química Nova, v. 19, n. 5, p. 529-536, 1996.

MENEZES, H. Própolis: uma revisão dos recentes estudos de suas propriedades farmacológicas. Arquivos do Instituto Biológico, v. 72, n. 3, p. 405-411, 2005.

MONZOTE, L.; CUESTA-RUBIO, O.; FERNANDEZ, M. C. et al. In vitro antimicrobial assessment of Cuban propolis extracts. Memórias do Instituto Oswaldo Cruz. v. 107, n. 8, p. 978-984, 2012.

OLIVEIRA, A. P.; FRANÇA, H. S.; KUSTER, R. M. et al. Chemical compositon and antibacterial activity of Brazilian propolis essential oil. Journal of Venomous Animals and Toxins including Tropical Diseases, v. 16, n. 1, p. 121-130, 2010.

PARK, Y. K.; ALENCAR, S. M.; SCAMPARINI, A. R. P. et al. Própolis produzida no sul do Brasil, Argentina e Uruguai: evidências fitoquímicas de sua origem vegetal. Ciência Rural, v. 32, n. 6, p. 997-1003, 2002. 
RIGHI, A. A.; ALVES, T. R.; NEGRI, G. et al. Brazilian red propolis: unreported substances, antioxidant and antimicrobial activities. Journal of the Science of Food and Agriculture, v. 91, n. 6, p. 2363-2370, 2011.

SFORCIN, J. M.; FERNANDES, J. R. A.; LOPES, C. A. M. et al. Seasonal effect on Brazilian propolis antibacterial activity. Journal of Ethnopharmacology, v. 73, p. 243-249, 2000.

SIQUEIRA, A. B. S; GOMES, B. S.; CAMBUIM, I. et al. Trichophyton species susceptibility to green and red propolis from Brazil. Letters in Applied Microbiology, v. 48, p. 90-96, 2009.

VARGAS, A. C.; LOGUERCIO, A. P.; WITT, N. M. et al. Atividade antimicrobiana "in vitro" de extrato alcóolico de própolis. Ciência Rural, v. 34, n. 1, p. 159-163, 2004.

VEIGA JUNIOR, V. F.; PINTO, A.C. Plantas medicinais: Cura segura? Química Nova, v. 28, n. 3, p. 519-528, 2005.

VIEGAS JR., C.; BOLZANI, V.S. Os produtos naturais e a química medicinal moderna. Química. Nova, v. 29, n. 2, p. 326-337, 2006.

VILELA, C. O.; FISCHER, G.; CASTRO, C. C. et al. Virucidal activity of green propolis against avipoxvirus in chorioallantoic membrane of embryonated chicken eggs. African Journal of Microbiology Research, v. 5, n. 9, p. 1075-1082, 2011. 